Journal of BANKING \& FINANCE

\title{
Sources of risk and expected returns in global equity markets
}

\author{
Wayne E. Ferson ${ }^{a}$ and Campbell R. Harvey*b,c \\ ${ }^{a}$ Department of Finance and Business Economics DJ-10, University of Washington, Seattle, WA \\ 98195, USA \\ ${ }^{b}$ The Fuqua School of Business, Duke University, Durham, NC, USA \\ ${ }^{\mathrm{c}}$ National Bureau of Economic Research, Cambridge, MA, USA
}

Received December 1992, final version received March 1993

\begin{abstract}
This paper empirically examines multifactor asset pricing models for the returns and expected returns on eighteen national equity markets. The factors are chosen to measure global economic risks. Although previous studies do not reject the unconditional mean variance efficiency of a world market portfolio, our evidence indicates that the tests are low in power, and the world market betas do not provide a good explanation of cross-sectional differences in average returns. Multiple beta models provide an improved explanation of the equity returns.
\end{abstract}

Key words: Global asset pricing; Exchange-rate risk; Generalized method of moments JEL classification: $\mathrm{F} 3$; G0; G1; C5

\section{Introduction}

This paper studies the sources of risk and average returns in international equity markets. We examine several measures of global economic risks and

\footnotetext{
* Corresponding author. Tel: 919-660-7768. Part of this research was conducted at the University of Chicago, Graduate School of Business and was circulated by the authors under another title. We thank Warren Bailey, Eugene Fama, Stephen Foerster, Kenneth French, Richard Green, Allan Kleidon, Johnny Liew, John D. Martin, L.T. Nielsen, Bruno Solnik, an anonymous referee, and participants in workshops at the Universities of California at Berkeley, Chicago, Florida, Iowa, Manitoba, Stanford, Texas at Austin, Texas at Dallas, Queens, Washington at Seattle, at the August, 1991 National Bureau of Economic Research Summer Institute's International Studies/Macroeconomics week, the 1992 Utah Winter Finance Conference, the 1992 Western Finance Association, the 1992 French Finance Association and the September, 1992 Berkeley Program in Finance for helpful discussions. Ferson acknowledges financial support from the Pigott-Paccar professorship at the University of Washington.
} 
ask to what extent these risk factors can explain the fluctuations in the stock markets of eighteen countries. The monthly risk measures include the returns on a world equity market portfolio, a measure of exchange risk, a Eurodollar - U.S. Treasury bill yield spread, and measures of global inflation, real interest rates, and industrial production growth. We find that the global risk factors can explain, ex-post, between $15 \%$ and $86 \%$ percent of the variance of the monthly returns over the 1970-1989 period. The world market portfolio is by far the most important factor. It alone can explain between $16 \%$ and $71 \%$ of the variance, depending on the country.

We examine the average return premiums associated with these global risks and we find significant premiums associated with the world equity index and a measure of exchange rate fluctuations, but no significant average premium associated with the other variables. Previous studies (e.g. Cumby and Glen, 1990; and Harvey, 1991a) do not reject the unconditional meanvariance efficiency of the world market index. We confirm this finding in our sample using a general test. However, we find that the power of the world market betas to explain the average return differences across the countries is low. The average pricing errors of the model are reduced by introducing the additional global risk factors. The average performance of the Japanese equity market, for example, is much better explained by a model which incorporates multiple sources of risk.

The paper is organized as follows. Section 2 outlines the methodology. Section 3 describes the country returns and the global risk factor data. The empirical results are presented in Section 4. Section 5 summarizes our conclusions.

\section{Methodology}

We first examine factor model regressions for the equity market index returns for eighteen countries:

$$
r_{i t}=\alpha_{i}+\sum_{j=1}^{K} \beta_{i j} F_{j t}+u_{i t} .
$$

The excess return is $r_{i t}=R_{i t}-R_{f t}$, where $R_{i t}$ is the U.S. dollar return for country $i$ at time $t$. $R_{f t}$ is the dollar return of a one-month U.S. Treasury bill. (We also report results for excess returns in local currency units.) The $\beta_{i j}$ are the betas of the $r_{i t}$ on the $K$ risk factors $F_{j}, j=1, \ldots, K$. The error terms, $u_{i t}$ represent the 'nonsystematic' excess returns, relative to the global risk factors.

We estimate most of our empirical models using Hansen's (1982) generalized method of moments (GMM), which is valid under mild statistical assumptions. In Eq. (1), we assume that the data vector, which is $\left\{r_{i t}\right.$, $\left.i=1, \ldots, N, F_{j t}, j=1, \ldots, K\right\}, t=1, \ldots, T$, is generated by a strictly stationary 
and ergodic stochastic process. The $\alpha_{i}$ and the $\beta_{i j}$ are fixed regression coefficients, which implies $E\left(u_{i t}\right)=E\left(u_{i t} F_{j t}\right)=0$. The error terms $u_{i t}$ are not assumed to be normally distributed, and the conditional variances of the $u_{i t}$, given the $F_{j t}$, may depend on the values of the $F_{j t}$. We do not specify the functional form of this possible dependence. Instead, we report the asymptotic standard errors for the cocfficients described by White (1980) and Hansen (1982). Hansen shows that the GMM coefficient estimators are consistent and asymptotically normal, derives their standard errors, and discusses the statistical assumptions more formally.

The factor model regressions provide information about the usefulness of global factors in controlling the risks of international equity investments. We are therefore interested in the factor models for their own sake. We are also interested in the relation between the risk sensitivities, $\beta_{i j}$, and the expected returns in the various national markets.

Asset pricing models attribute cross-sectional differences in expected returns to differences in betas. A general beta pricing model asserts the existence of expected premiums $\lambda_{j}, j=0, \ldots, K$; such that expected returns can be written as:

$$
E\left(R_{i}\right)=\lambda_{o}+\sum_{j=1}^{K} b_{i j} \lambda_{j}
$$

The $b_{i j}$ are the betas (multiple regression coefficients) of the $R_{i t}$ on the $K$ global risk factors $j=1, \ldots, K$. Eq. (2) implies an expression for the expected excess returns:

$$
E\left(r_{i}\right)=\sum_{j-1}^{K} \beta_{i j} \lambda_{j} .
$$

where $\beta_{i j}=b_{i j}-b_{f j}$ are the betas of the excess returns and the $b_{f j}$ are the betas of the Treasury bill.

Beta pricing models for expected returns like Eqs. (2) and (3) are familiar in a domestic context and are developed for an international setting by a number of authors. In order to apply a beta pricing model in a global setting, strong assumptions are needed. The national equity markets are assumed to be perfectly integrated in a global economy, with no barriers to extranational equity investments, no taxes, no transactions or information costs. Such extreme assumptions are unlikely to provide a good approximation to the actual complexity of international investments. Therefore, we interpret our results as a baseline case. Further refinements of the models, to incorporate additional considerations should produce even better explanatory power. Such refinements remain an important topic for future research.

The number and identity of the global risk factors takes on special significance in an international setting. We study models with a single factor 
and with multiple factors. The single factor model is a global version of the Capital Asset Pricing Model (CAPM) of Sharpe (1964) and Lintner (1965), which states that the world market portfolio is mean-variance efficient. Stulz (1981b, 1984) and Adler and Dumas (1983) provide conditions under which a single-beta CAPM based on the world market portfolio holds globally. The sufficient conditions are strong, including no exchange risk and a constant investment opportunity set, in addition to the assumptions described above.

When strict purchasing power parity fails to hold, then consumers face exchange risks for investing internationally, and exchange risks may be priced in a global asset pricing model. Adler and Dumas (1983, Eq. 14) present a model in which a combination of the world market and measures of exchange risk is mean variance efficient. The exchange risk can be broken down into a separate factor for each currency, as in Dumas and Solnik (1992), or can be approximated by a single variable. We take the latter approach and study a two-beta model, using the world market portfolio and an aggregate of exchange risks as the two factors.

International equilibrium and APT models with several factors are described by Stulz (1981a), Hodrick (1981), Solnik (1983) and Ross and Walsh (1983), among others. A central intuition of such models is that the common sources of risk may command an expected return premium, while risks that can be diversified internationally should not. Korajczyk and Viallet (1989) and Heston et al. (1991) find evidence of several common sources of variation in individual U.S. and European stocks. Given evidence for several common sources of variation, a number of world-wide risk factors may be important determinants of national equity market returns. We therefore study models with a number of global economic risk variables.

Eqs. (2) and (3) are a stylized representation for a class of beta pricing models, and the content of the model is the discipline imposed in selecting the factors. Our approach is to choose the variables a priori and to investigate their importance using the factor model regressions (1). Then, we study the pricing of the most important risk factors. Our focus in this paper is on the relation between risk and long-run expected returns. That is, we investigate unconditional versions of the beta pricing models. ${ }^{1}$

We estimate and test the pricing Eq. (3) as a restricted seemingly unrelated regression model (SURM):

$$
r_{i t}=\sum_{j=1}^{K} \beta_{i j}\left(f_{j t}+\lambda_{j}\right)+u_{i t}, \quad i=1, \ldots, N,
$$

where the $f_{j}$ are the de-meaned values of the risk factors $\left(f_{j t}=F_{j t}-\bar{F}_{j}\right.$ and $\bar{F}_{j}$

\footnotetext{
' See Ferson and Harvey (1993) for an examination of conditional asset pricing models using similar variables.
} 
is the sample mean). The regression is restricted by assuming that the intercept is equal to zero. The theoretical model, Eq. (3), implies that $E\left(u_{i t}\right)=0$ in Eq. (4). The parameters to be estimated are the unconditional betas, $\beta_{i j}$ and the expected risk premiums, $\lambda_{j}$. Since $E\left(f_{j t}\right)=0$, we do not assume in Eq. (4) that the means of the factors $F_{j}$ are related in any way to the expected risk premiums $\lambda_{j}$. This allows us to use economic variables as factors and to estimate and test the model without the need for mimicking portfolios for the factors. ${ }^{2}$ This is an advantage over the approaches of Gibbons (1982), Breeden et al. (1989) and others, since the estimation of mimicking portfolios in a separate step can complicate the statistical inferences (see Wheatley, 1989).

We implement the SURM via the GMM. We therefore assume that the data vector $\left\{r_{i t}, i=1, \ldots, N, f_{j t}, j=1, \ldots, K\right\}, t=1, \ldots, T$, is generated by a strictly stationary and ergodic stochastic process. As before, we avoid the usual assumptions of homoskedasticity and normality, which are unlikely to hold in these data. We use a vector of ones and the contemporaneous values of the factors, $F_{j t}$ as the instruments in the GMM. The orthogonality conditions therefore state that $E\left(u_{i t} F_{j t}\right)=0$ and $E\left(u_{i t}\right)=0$, for all $i=1, \ldots, N$ and $j=1, \ldots, K .^{3}$

\section{The data}

\subsection{The asset returns}

We study equity returns in eighteen national markets using monthly data provided by Morgan Stanley Capital International. The countries include sixteen OECD countries plus Singapore/Malaysia and Hong Kong. The country returns are value-weighted indices formed from a list of 1476 (as of December, 1989) companies. The firms represent about $65 \%$ of the market capitalization of the countries' stock markets, with some attempt to stratify the sample by industry groups, so that each industry is represented in proportion to its national weight (see Schmidt, 1990). The stocks are generally those for which the total market value outstanding is large. Total monthly returns are measured for 1970-1989 as the capital change component of a country index plus the dividend yield, as provided by $\mathrm{MSCl}^{4}$

\footnotetext{
${ }^{2}$ Mimicking portfolios are defined as portfolios that may be substituted for the factors in a factor model regression and whose expected excess returns are the risk premiums (e.g. Lehmann and Modest, 1988; Huberman et al., 1987).

${ }^{3}$ We use iterated GMM following Ferson and Foerster (1993), who found that such an approach has superior finite sample properties when compared with a two step procedure.

${ }^{4}$ The dividend yield is $1 / 12$ of the previous year's dividend divided by the level of the index at the end of a month. See the appendix for details.
} 
When measured in U.S. dollars the returns are in excess of the U.S. Treasury bill that is the closest to 30 days to maturity, provided by the Center for Research in Security Prices (CRSP) at the University of Chicago. When measured in local currency units the returns are in excess of a local short term interest rate from Citibase or the International Monetary Fund (IMF) (see the appendix for details). To convert from local currency values to U.S. dollar values, the closing European interbank currency rates from MSCI are used on the last trading day of the month. The world equity market index is a value-weighted combination of the country returns. ${ }^{5}$

\subsection{The global economic risk variables}

Summary statistics for the variables are presented in Table 1. We include a brief discussion of each global risk variable here; details are provided in the appendix.

WDRET is the U.S. dollar return of the MSCI world equity market in excess of a short term interest rate. Asset pricing models usually include a role for a 'market portfolio' as a measure of risk. Cumby and Glen (1990) test and do not reject the unconditional mean variance efficiency of the world market index. Harvey (1991a) does not reject the unconditional efficiency of the MSCI index in the set of MSCI country returns, but he does reject the conditional efficiency of the index. This raises the likelihood that previous tests are low in power. Fama and French (1992) find that unconditional betas on market indexes in the U.S. do not provide a good cross-sectional explanation of expected returns. It is therefore interesting to further examine the usefulness of a world beta to explain the country returns.

dGIOFX is the $\log$ first difference in the trade-weighted U.S. dollar price of the currencies of 10 industrialized countries. The G-10 countries are defined as the G-7 (not including the U.S.) plus the Netherlands, Belgium, Sweden and Switzerland. (The G-7 countries are Canada, France, Germany, Italy, Japan, the United Kingdom, and the United States.) This series is taken from the IMF as reported by Citibase. A positive change $(\mathrm{dG} 10 \mathrm{FX}>0)$ indicates a depreciation of the dollar. In Adler and Dumas (1983, Eq. 14), an exchange

\footnotetext{
${ }^{5} \mathrm{MSCl}$ attempts to avold the double counting of firms whose equity is traded on the stock markets of more than one country. There are, however, other problems with the index. French and Poterba (1991) show that the MSCI world index gives too much weight to Japan because the amount of cross corporate ownership of shares in Japan has been unusually high. Alternative indices, such as the FT-Actuaries world index, suffer from the same problem. Harvey (1991a) reports that in March of 1989 Japan accounted for $43 \%$ of the MSCI world index and $41 \%$ of the FT-Actuaries index. We choose the MSCI data over the FT-Actuaries data, because the latter are only available from 1981.
} 
risk factor appears, which depends on exchange rates, consumer price index changes, and risk tolerance in each country. This theoretical measure is difficult to replicate empirically, so Dumas and Solnik (1992) break it down into separate factors for each country. We use a single aggregate measure as a parsimonious alternative to the approach of Dumas and Solnik (1992). Previous studies examine the pricing of exchange risks in national equity markets. They find little evidence that exchange risks are priced on average domestically, but we address a different question. We examine the pricing of a global measure of exchange risk in a multi-country asset pricing model.

$G 7 U I$ is the unexpected component of a monthly global inflation measure. The G-7 inflation rate is a weighted average of the percentage changes in the consumer price indices (CPI) in the G-7 countries, using the relative shares of the total real, gross domestic product (GDP) as the weights. Inflation risk can be priced in a multi-beta model if inflation has real effects, in the general sense that global inflation is correlated with a representative investor's marginal utility. For example, higher inflation may signal higher levels of economic uncertainty which make consumers worse off. If national equity market returns differ in their exposure to changes in the global inflation outlook, there may be an inflation risk premium on global equity markets.

$d G 7 E L T$ is the monthly change in a measure of long-term inflationary expectations. Chen, Roll and Ross (1986) include a measure of U.S. unexpected inflation and a measure of changes in expected U.S. inflation in their study for the U.S. We examine the pricing of global inflation on world markets. dG7ELT is formed by regressing a 48-month moving average of the G-7 inflation rate on a set of predetermined instruments and taking the first difference of the fitted values.

dTED is the change in the spread between the 90-day Eurodollar deposit rate and the 90 day U.S. Treasury bill yield. The 'TED spread' is a measure of the premium on Eurodollar deposit rates in London, relative to the U.S. Treasury. Fluctuations in the spread may capture fluctuations in global credit risks.

$G 7 R T B$ is a weighted average of short-term real interest rates in the G7 countries, using the shares of G-7 GDP as the weights, minus the G7 inflation rate. Real interest rates are often used in economic models to capture the state of investment opportunities. For example, Merton (1973) and Cox, Ingersoll and Ross (1985) develop models in which interest rates are state variables. Chen, Roll and Ross (1986) and Ferson and Harvey (1991) include a real interest rate state variable in models for the U.S. market. ${ }^{6}$

\footnotetext{
${ }^{\circ}$ Although the correlation between G7RTB and G7UI is relatively high (at -0.56 ), it is not perfect because the G7 nominal interest rates are not part of the conditioning information used to form G7UI and because G7RTB is not prewhitened.
} 


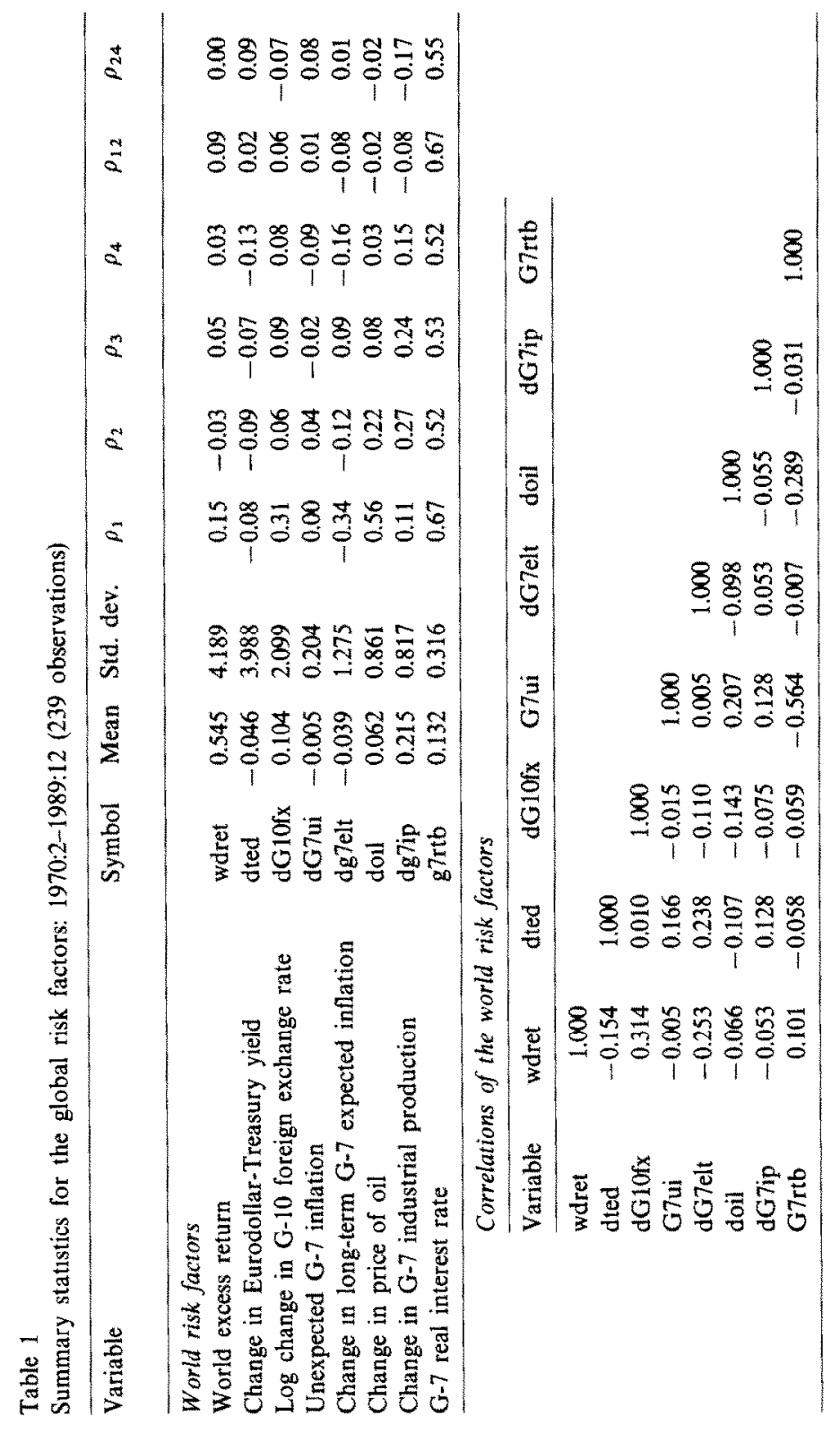




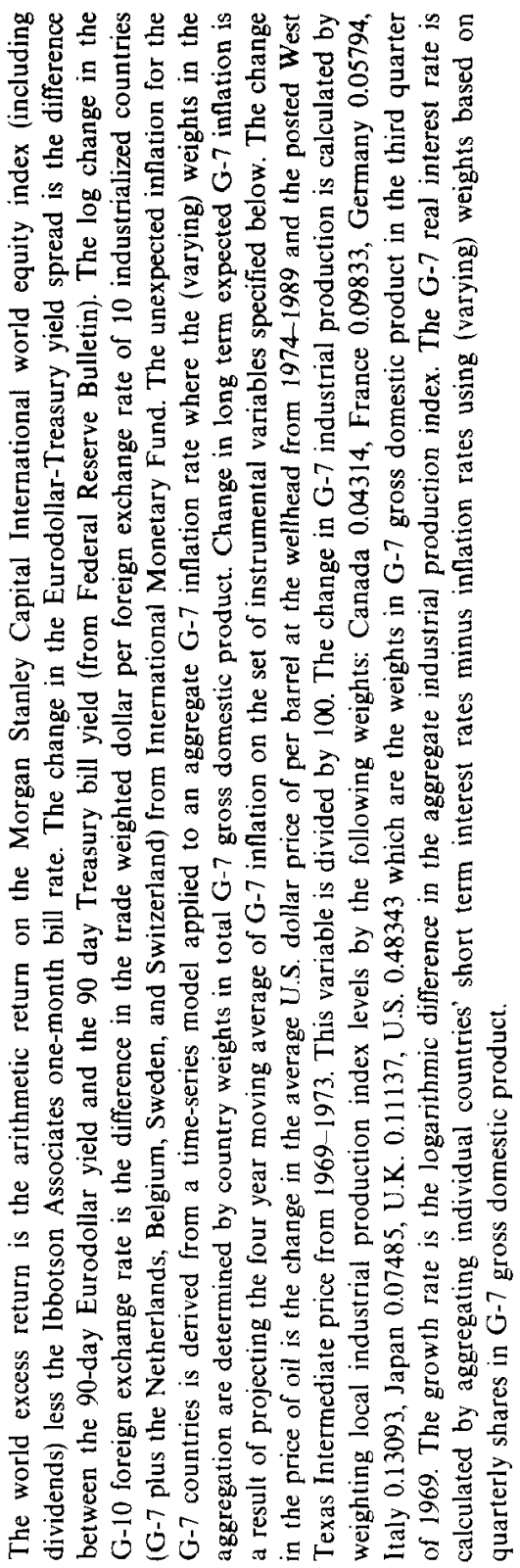


$d O I L$ is the change in the monthly average U.S. dollar price per barrel of crude oil. ${ }^{7}$ A number of studies have examined premiums for oil price risk exposure using a cross-section of assets with a country. For example, Chen, Roll and Ross (1986) study oil prices as a measure of economic risk in the U.S. market and Hamao (1988) and Brown and Otsuki (1990b) study oil prices in the Japanese equity market. We study oil prices as a potential source of global market risk, to which different national markets may have differing exposures.

$d G 7 I P$ is a weighted average of industrial production growth rates in the G7 countries, using a measure of relative production shares as the weights. Chen, Roll and Ross (1986) and Shanken and Weinstein (1990) examine the average pricing of U.S. industrial production in the U.S. market. Hamao (1988) examines domestic industrial production risk in the Japanese equity market and Bodurtha, Cho and Senbet (1989) study average risk premiums for domestic industrial production risks in several national equity markets. No previous study has examined the average pricing of global industrial output risks.

\section{Empirical results}

\subsection{Factor models}

Table 2 presents factor model regressions (1) for each country using the eight global risk factors. The right hand columns of the table show the adjusted $R$-squares for three cases. In the far right column only a constant and the world market index are in the regressions. In the other two columns additional factors are added. The increment to the $R$-squares from including the other economic variables is small for most of the countries. ${ }^{8}$ The world market portfolio is by far the most important factor from the perspective of explaining variance.

The panel at the bottom of Table 2 presents heteroskedasticity consistent

\footnotetext{
${ }^{7}$ We use a spliced series of the posted west Texas intermediate crude and the average U.S. wellhead price, as described in the appendıx. These are not the best indicators of market prices, but they are the best avallable to us for this period. Futures markets for crude oll did not develop until 1983 (heating oll futures began trading in 1978). Chen et al. (1986) used the energy component of the producer price index. Given the prevalence of long term oil price contracts over much of the sample, this measure is not likely to better reflect current oll market conditions.

${ }^{8}$ This is consistent with the evidence of Wasserfallen (1989) who finds little sensitivity of international stock returns to macroeconomic news. However, Wasserfallen uses the residuals from a vector autoregression as his factors, while in Table 2 we define innovations relative to the unconditional means.
} 
Wald tests of the hypothesis that a risk factor has unconditional betas equal to zero for all of the countries. We do not reject this hypothesis for the variables dTED, G7UI, dG7IP and G7RTB; the hypothesis is rejected for the other four variables. If the beta coefficients for a particular variable are not significantly different from zero in the factor model regressions, this suggests dropping the variable from the analysis. Obviously, if the beta is zero the factor is not useful for controlling variance. Similarly, their can be no expected return premium for a factor whose betas are all zero. However, a small nonzero beta could be associated with an important average risk premium. For example a risk factor could have low correlation with asset returns but high correlation with the aggregate marginal utility of wealth.

If a risk variable does not have different coefficients across the countries then it cannot be priced even if the betas differ from zero. This is because unconditional pricing implies that expected returns differ across countries depending on differences in their sensitivities to the variable. The point estimates suggest that there are significant differences in the countries' sensitivities to several of the variables. For example, the Japanese stock market is significantly positively-related to changes in long term inflationary expectations, while the Australian market is negatively-related to the same factor. The equity markets of Hong Kong and Singapore/Malaysia are positively-related to oil price changes, while in Spain the relation is negative.

The lower panel of Table 2 presents tests of the hypothesis that a given factor has betas which are equal to a common value in all of the countries. We do not reject this hypothesis for the same set of variables for which we do not reject that the betas are jointly zero (and therefore equal). On the basis of these tests, we exclude the variables dTED, G7UI, dG7IP and G7RTB from our empirical model and we retain the other variables (WRDRET, dG10FX, dG7ELT, and dOIL). ${ }^{9}$

\subsection{Expected returns and global economic risks}

Table 3 presents the results of the SURM, Eq. (4), for two cases. The three columns on the left present a model where the world market index is the only factor. The five columns on the right present a four-factor model. The first column reports the excess return betas on the world market index, which vary from 0.38 (Austria) to 1.3 (Hong Kong). The beta in the SURM's

\footnotetext{
${ }^{9}$ We replicated the tests in Table 2 using only G7UI or only dG7ELT as the inflation variable. The test results for the two inflation variables, as well as the other six risk factors, were not sensitive to which of the inflation variables was included, or if both were included. Thus, dG7ELT does not appear to proxy for unexpected inflation in these data. We also found that the coefficients on the world market index for most of the countries, as presented in Table 2, are similar to therr simple regression betas on only the world market index.
} 


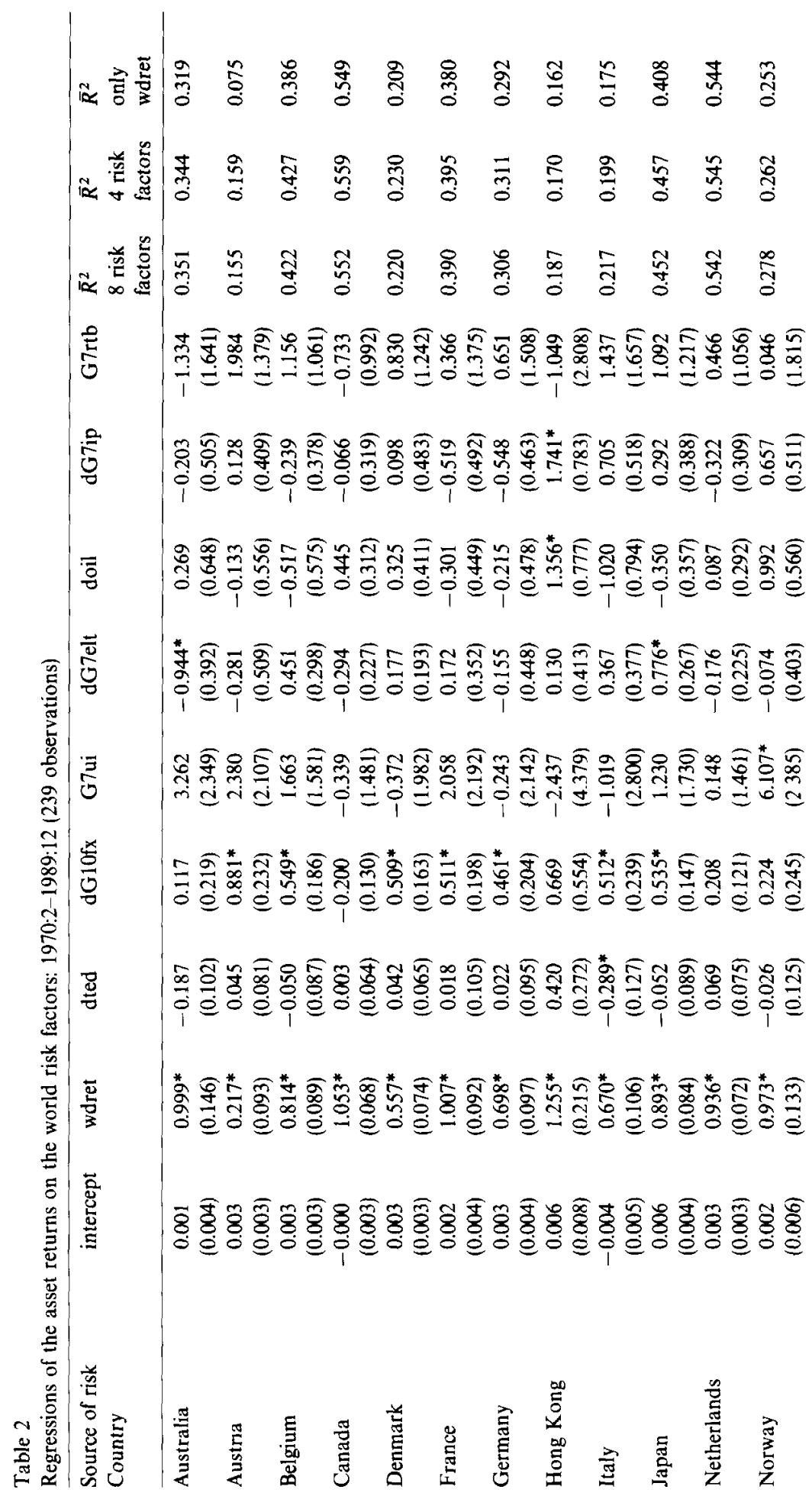




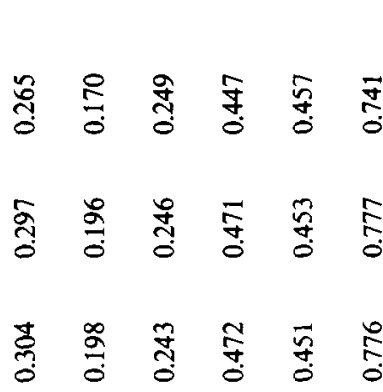

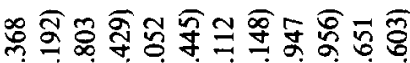

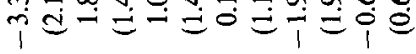

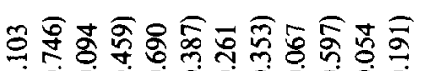

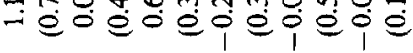

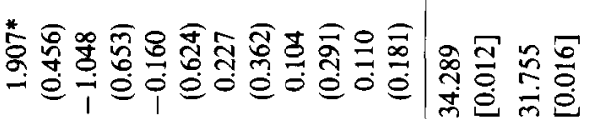

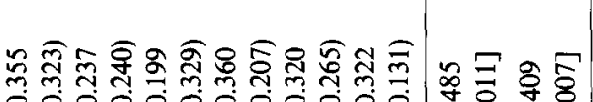

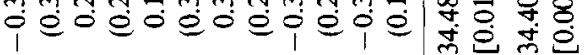

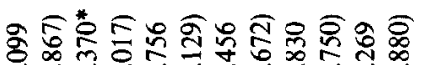

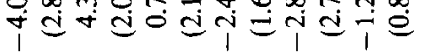

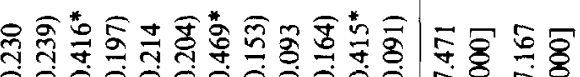
त仓

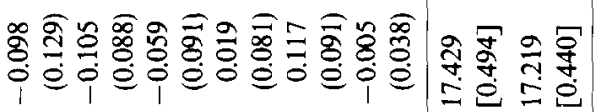

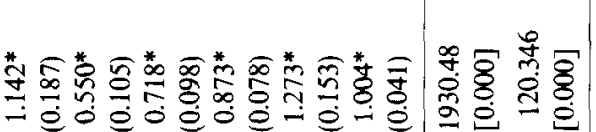

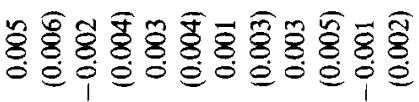
岕灾苛

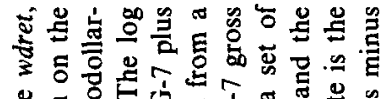

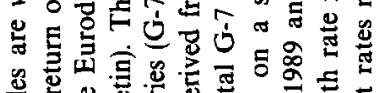

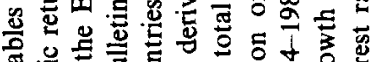

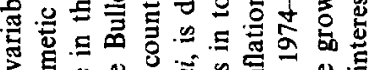

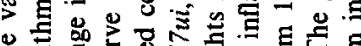

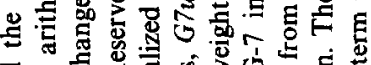

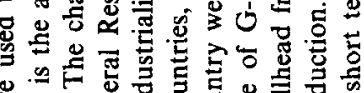

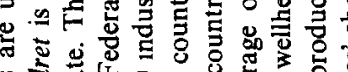

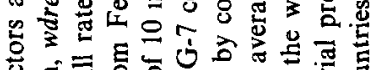

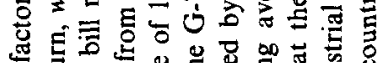

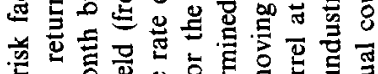

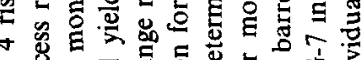

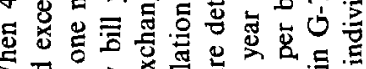

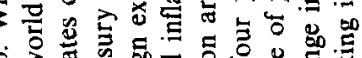

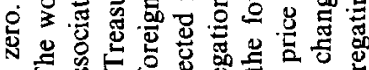

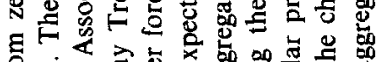

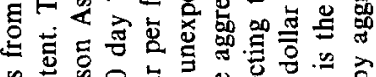

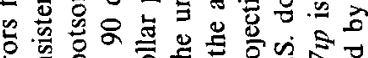

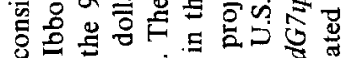

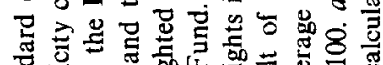

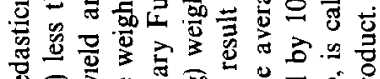

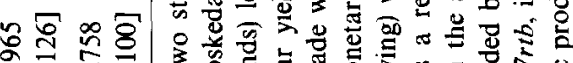

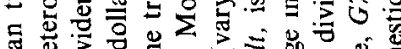

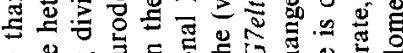
을

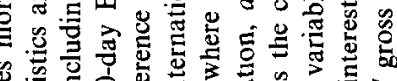

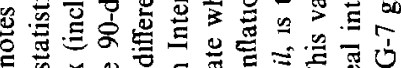

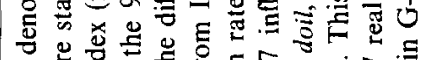

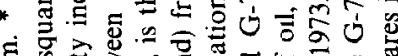

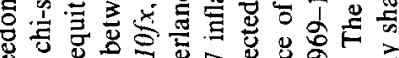

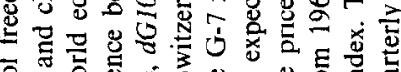

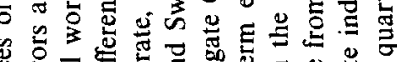

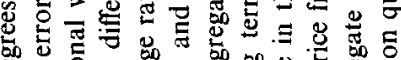

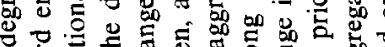

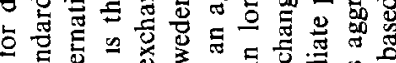

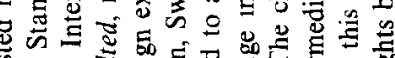

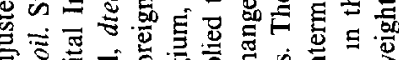

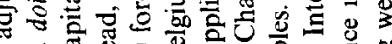

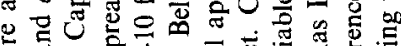

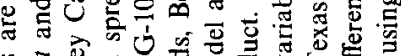

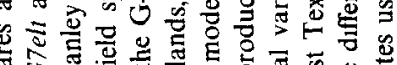

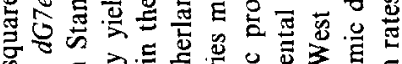

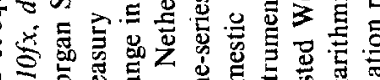

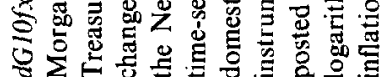




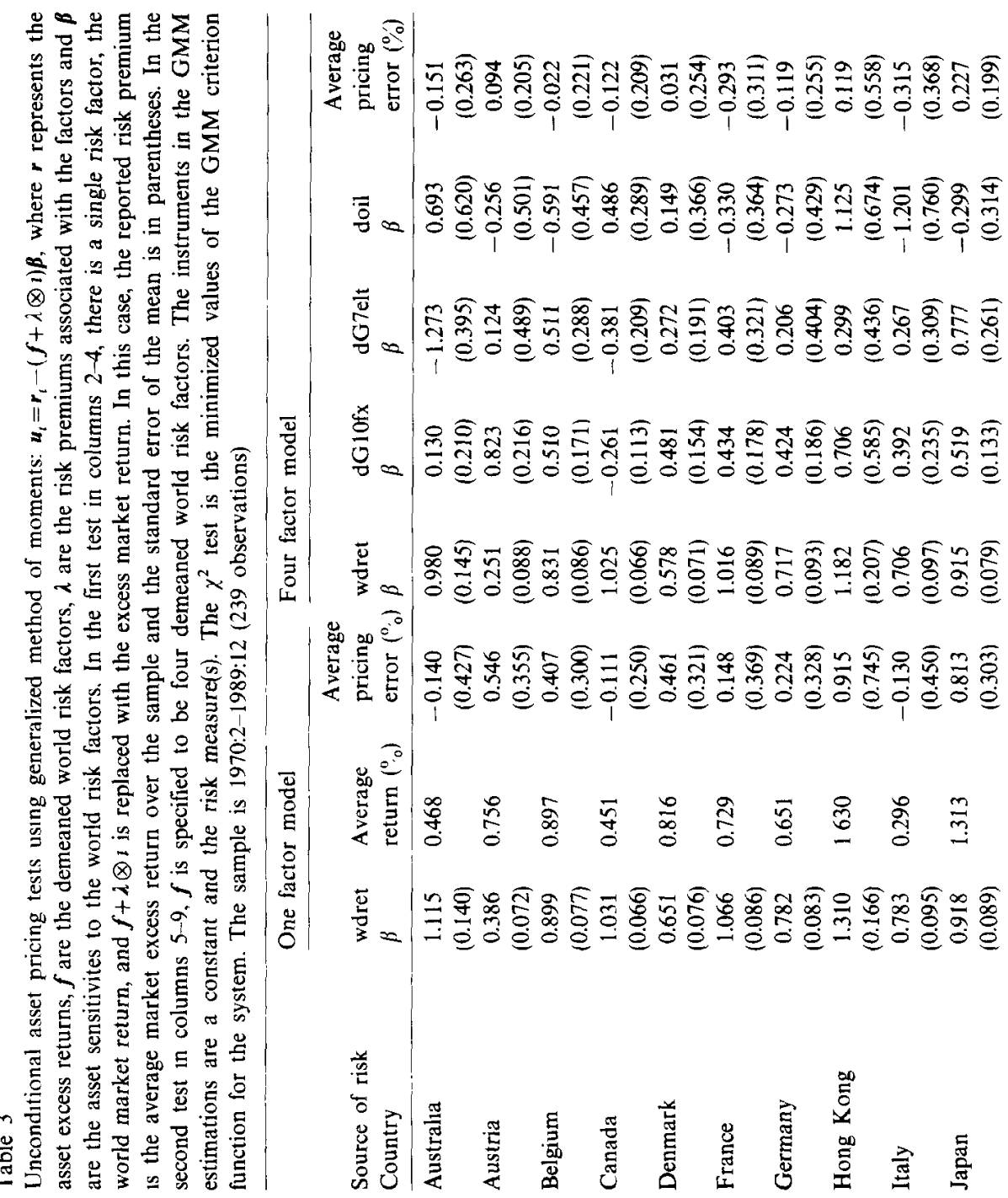




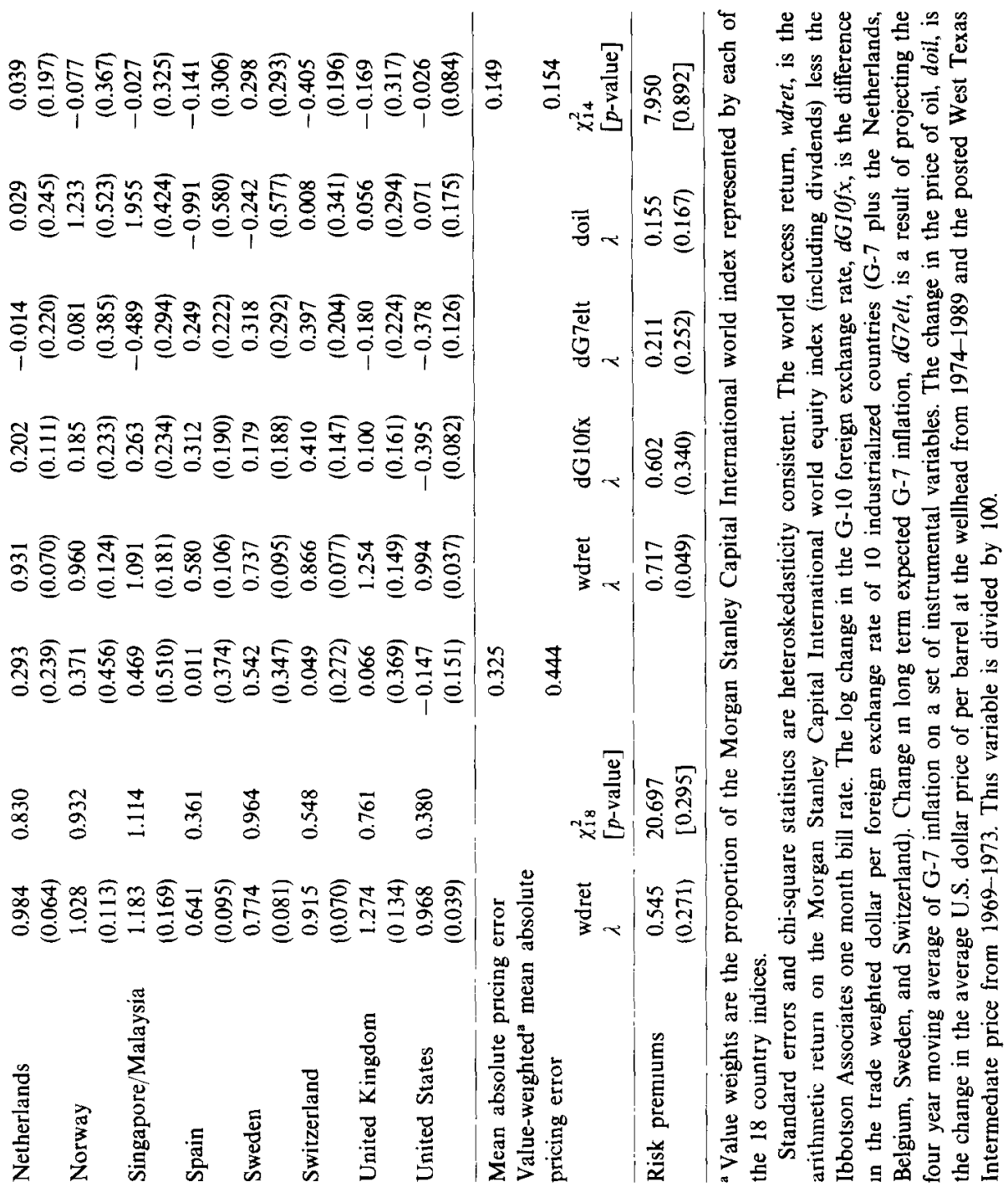


are very close to the betas in the unrestricted regression models. The two world market beta estimates never differ by more than one standard error for a given country.

In the single-factor model with the world market factor, the factor is the excess return of a portfolio. In such a case, Shanken (1992) shows that the best estimate of the risk premium is the expected excess return itself. For the one-factor model we therefore impose the restriction that the expected risk premium $\lambda_{1}$ is equal to the expected excess return of the world market index. The expression $\left(f_{1 t}+\hat{\lambda}_{1}\right)$ in (4) is replaced by $r_{m t}$, and the number of free parameters in the SURM is reduced by one. The goodness of fit statistic for the restricted SURM implies a right-tailed $p$-value of 0.295 , thereby not rejecting the hypothesis that the world market portfolio is unconditionally mean-variance efficient. This is consistent with the tests in Cumby and Glen (1990) and Harvey (1991a). However, further investigation suggests that such joint tests are low in power.

The point estimate of the world market risk premium is 0.545 and its standard crror is 0.271 , which seems reasonable. But the pricing errors of the one-factor model for many of the countries are large. The average pricing errors are defined as the difference between the average country returns and the expected returns predicted by the model, evaluated at the sample estimates. The model leaves economically large pricing errors of $0.8 \%$ (standard error $=0.3 \%$ ) per month for Japan and $0.9 \%$ (standard error $=0.7 \%$ ) per month for Hong Kong. The standard errors for the average pricing errors are calculated as in Hansen (1982, lemma 4.1), which accounts for the fact that the pricing errors are evaluated at the GMM point estimates of the parameters. ${ }^{10}$ Of course, it is hazardous to focus on the pricing errors which are the largest in a group of estimates, and to apply these standard errors to judge their significance. This is because the multiple comparisons implied by selecting the largest values are not accounted for in the individual standard errors. Still, the pricing errors suggest that the Japanese and Hong Kong stock markets out performed the world market on a beta adjusted basis over this period, while Canada, Italy and the United States have been poor performers on the same basis.

The panel below the individual country results in Table 3 reports the mean absolute pricing error and a value-weighted average absolute pricing error as

\footnotetext{
${ }^{10}$ The GMM parameter estimates are found by minimizing a quadratic form, $g^{\prime} W g$, where $W$ is the fixed weighting matrix, the inverse of a consistent estimate of the covariance matrix of the orthogonality conditions, $g$, at the true parameter values. Our pricing error is the sample mean of one of the orthogonality conditions, evaluated at the point estimates. Let $g d$ be the sample mean of the gradient of the orthogonality conditions with respect to the parameter vector. The formula for the covariance matrix of the sample mean of the orthogonality conditions is: $\left[W^{-1}-g d\left(g d^{\prime} W g d\right)^{-1} g d^{\prime}\right] / T$. The covariance matrix is evaluated at the consistent sample estimates.
} 
alternative summary measures. The value weights are the weights of the countries in the MSCI world index as of the first quarter of 1989 . The valueweighted average absolute pricing error is larger ( $0.44 \%$ per month) than the equally weighted average $(0.33 \%$ per month) primarily because Japan receives a large weight, as we believe it should.

Thesc economically large deviations from the model, as represented by the pricing errors, are not sufficient to reject the efficiency of the world market index using the standard goodness-of-fit statistic. The joint test statistic combines the squared pricing errors together with the other orthogonality conditions, weighted by the precision with which they are estimated. The pricing errors may be large, but their precision is low, and the joint test statistic does not have enough power to reject the model.

Some additional exercises provide further evidence on the ability of the world market betas to explain the average returns. We use the cross-sectional methods of Fama and MacBeth (1973), estimating monthly regressions of the country returns on their unconditional world market betas. ${ }^{11}$ The results differ depending on whether the cross-sectional intercept is suppressed, as it is in the SURM, or included in the regression. With the intercept suppressed the slope coefficient, an estimate of the world market premium, is $0.819 \%$ per month (standard error $=0.085 \%$ ). However, when the intercept is included in the regression the slope coefficient is $0.469 \%$ (standard error $=0.349 \%$ ). The average of the adjusted $R$-squares in the monthly cross-sectional regressions is only $4 \%$. Although efficiency of the world market index is not rejected, the relation between the country returns and the world market betas is weak. ${ }^{12}$ This is also evident in Fig. 1, which plots the average returns against the world market betas.

The right-hand columns of Table 3 present the pricing results using the four global risk variables. The goodness-of-fit test does not reject the model, producing a large right-tail $p$-value of 0.892 . The average pricing errors for many of the countries are reduced in the multiple-beta model, relative to the single beta model. For example, the pricing errors are only $0.2 \%$ per month for Japan and $0.1 \%$ for Hong Kong. For a number of the other countries the

\footnotetext{
${ }^{11}$ The cross-sectional regression procedure of Fama and MacBeth (1973) assumes that the sccurity returns arc corrclated cross-sectionally and are heteroskedastic, which implies that the usual regression standard errors can be misleading. The time-series average of the monthly cross-sectional regression slopes is used as the estimate of the expected premium. The standard errors are calculated as the standard error of the mean using the time series of the monthly estimates. This assumes that the series of the monthly coefficient estimates (which are themselves portfolio returns) are uncorrelated over time. Shanken (1992) reviews the statistical assumptions required for the Fama-MacBeth approach and shows how it is related to maximum likelihood and other approaches.

${ }^{12}$ A single cross-sectional regression of the average excess returns on the world market betas, using the Table 3 estimates, produces an adjusted $R$-square of only $3.2 \%$.
} 


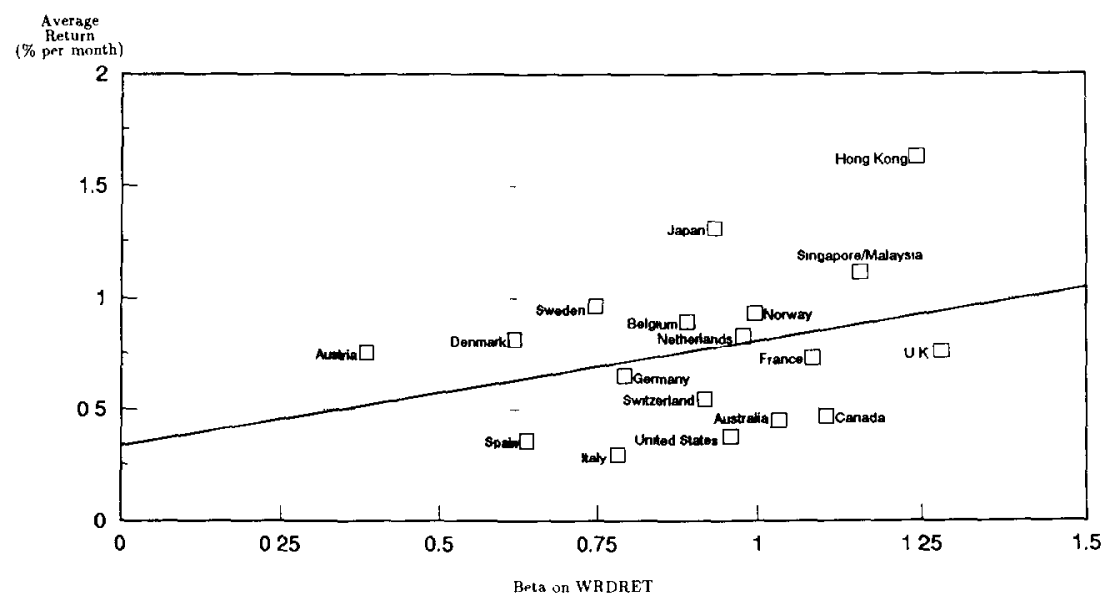

Fig. 1. Unconditional beta coefficients of country index returns calculated in U.S. dollars regressed on the world market return (WRDRET). The sample is February 1970-December 1989.

pricing errors are an order of magnitude smaller than they were using only the world equity portfolio to measure risk. Furthermore, the mean absolute error and the value-weighted mean absolute errors are substantially reduced. This suggests that when the measures of risk are expanded to include the other variables, then much of the seemingly abnormal average performance of the Japanese and Hong Kong markets may be explained as compensation for global economic risk. However, Canada, Italy and the U.S. markets still seem to have performed poorly on a risk adjusted basis.

The average risk premium in Table 3 for the exchange risk variable $\mathrm{dG} 10 \mathrm{FX}$ is $0.602 \%$ and is 1.8 standard errors from zero using the SURM. The average premiums for dG7ELT and dOIL are not individually statistically significant. Recall that $\mathrm{dG} 10 \mathrm{FX}$ is measured in dollars per local currency unit. All of the betas on this variable are positive (except for the US and Canada), indicating that when the dollar depreciates the dollar excess return of foreign stocks tends to rise. ${ }^{13}$

The estimated risk premium for the world market index appears strongly significant in the multiple beta SURM. Introducing the additional risk factors results in a slightly larger point estimate of the premium for the world market index. The standard error of that estimate is much smaller than in the single-factor model. The results for the multiple-factor model in Table 3 appear to be different from the results of Chen, Roll and Ross (1986)

\footnotetext{
${ }^{13}$ This is consistent with previous studies (e.g., Jorion, 1991) who measure exchange rates as dollars per currency unit and find positive (but insignificant) average premums.
} 
for the U.S., where the introduction of multiple risk factors reduced the average premium for the U.S. stock market index to a small, statistically insignificant number. We find that part of the explanation is a difference in the methodologies.

Chen, Roll and Ross (1986) used a cross-sectional regression approach which allowed for a nonzero intercept. In the SURM, the intercept is suppressed, as it should be zero under the null hypothesis. When we use cross-sectional regressions, similar to Fama and MacBeth (1973), which include an intercept and thereby estimate the multiple-beta model allowing an ad-hoc alternative hypothesis, the premium for the world market index is not significantly different from zero. ${ }^{14}$

\subsection{Sensitivity analysis}

Our sample covers the decades of the 1970's and 1980's, a period in which the international investment climate saw much change. Barriers to international investment which had been in place were removed or weakened in the latter parts of the 1970's and early 1980's in severa! countries. Some of the national market average returns are remarkably different in the two subperiods. For example, the average excess dollar return for Japan is $1.02 \%$ per month in the first half and $1.61 \%$ in the second half. For Italy, the average is $-0.67 \%$ in the first half and $1.27 \%$ in the second. It is interesting, therefore, to see if the last half of our sample produces qualitatively different results than does the first half. We estimate the SURM models for the first and second halves of our sample. Similar to the full period results, the test statistics do not reject the models. The average pricing errors are similar in the two subperiods. The value-weighted pricing error is $0.209 \%$ in the first half and $0.210 \%$ in the second half. The average pricing error for Japan is $0.346 \%$ in the first half and $0.229 \%$ in the second. The world market premium is significant in both subperiods; in fact the point estimate using the SURM is slightly larger in both subperiods than over the full sample. The premium for dOIL is $0.31 \%$ per month in the second subperiod and is significant, but the estimate is negative and insignificant in the first subperiod. A similar result is found for the foreign exchange risk variable. The premium estimate is positive in the first period and negative in the second. These results may indicate time-variation in the expected premiums.

To assess the sensitivity of our results to the use of US dollar excess returns, we change the definition of the returns to local currency units,

\footnotetext{
${ }^{14}$ In a single cross-sectional regression (with an intercept) of the average returns on the four betas from Table 3, the adjusted $R$-square is $71.2 \%$ and three of the four premiums appear significant. The world market premium has the smallest $t$-statıstic, equal to 1.74 .
} 


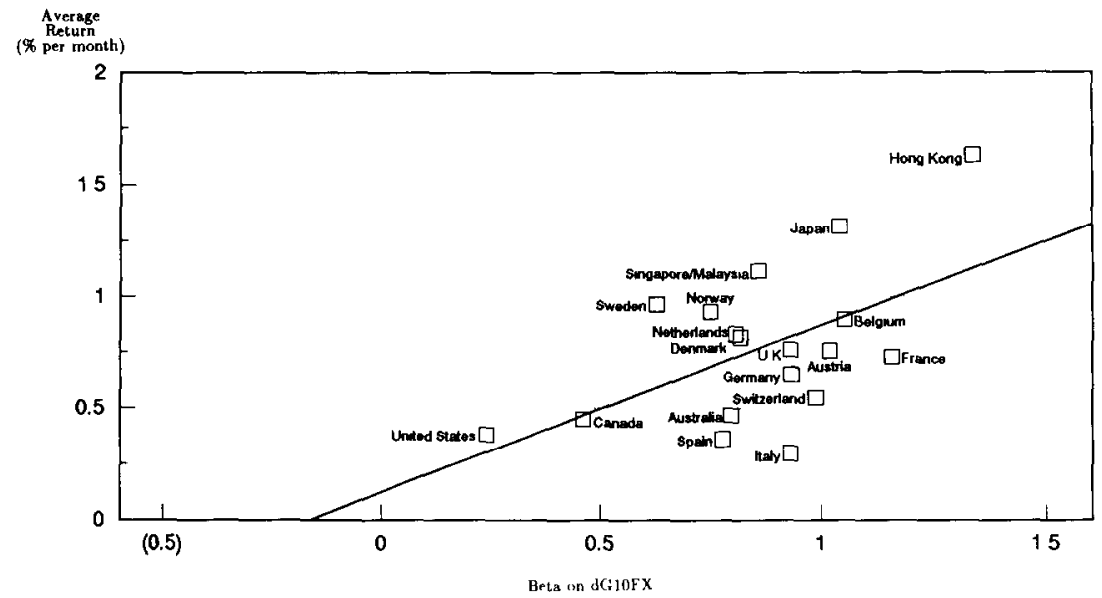

Fig. 2. Unconditional beta coefficients of country index returns calculated in U.S. dollars regressed on the log change in the trade-weighted U.S. dollar price of the currencies of 10 industralized countries (dG10FX). The sample is February 1970-December 1989.

measured in excess of a local short term interest rate. Such an excess return can be interpreted as a long position in the local stock market financed by local currency borrowing, and is therefore hedged against currency fluctuations to some extent. We find that the results on the average pricing of the world market index are virtually unaffected. ${ }^{15}$ However, the SURM estimates of the average premium associated with dG10FX are closer to zero and are not statistically significant. We examine univariate models with dG10FX and bivariate models with dG10FX and the world market index, using Fama-MacBeth (1973) methods. The average cross-sectional relation between returns and the betas on dG10FX are depicted in Fig. 2 (U.S. dollar returns) and Fig. 3 (local currency returns). These experiments generally confirm the results of the SURMs. ${ }^{16}$

Measurement errors in the economic data may reduce the correlation of the global risk measures with the country returns. We therefore conduct an additional set of tests using maximum correlation portfolios for the economic risk factors, similar to Breeden, Gibbons and Litzenberger (1989) and McCurdy and Morgan (1992). The portfolio weights are the slope coefficients of the economic variable regressed on the asset returns and are fixed over

\footnotetext{
${ }^{15}$ Korajczyk and Viallet (1989) report similar results in their study of four countries using a world CAPM and APT factors.

${ }^{16}$ The main exception is that when returns are measured in local currency units the average premium on dG10FX is marginally significant in the univariate and bivariate Fama-MacBeth models, while in the SURM and in the four-factor models the premium is not significant.
} 


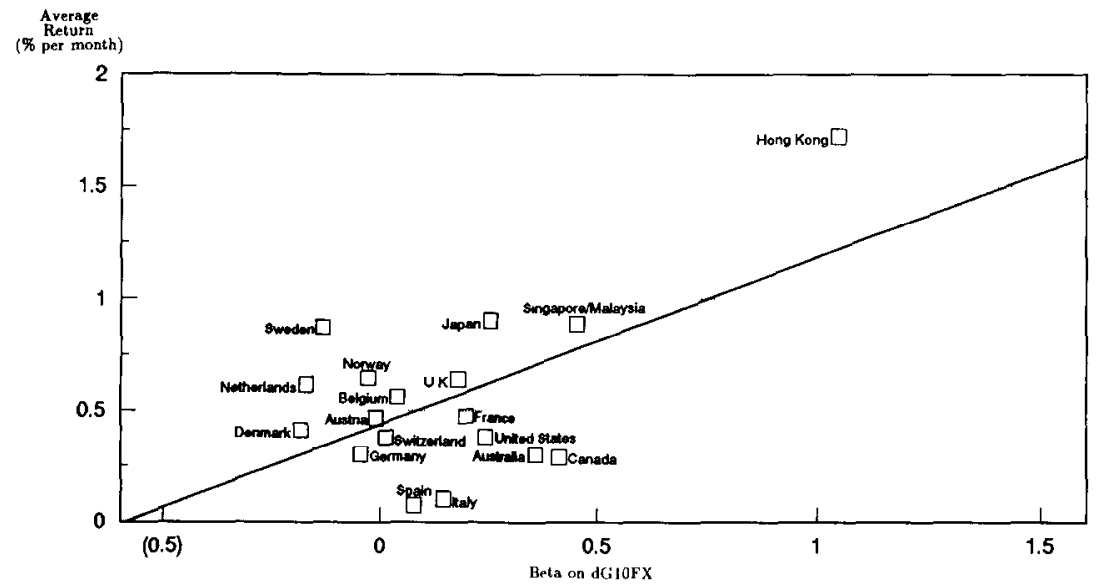

Fig. 3. Unconditional beta coefficients of country index returns calculated in local currency regressed on the log change in the trade-weighted U.S. dollar price of the currencies of 10 industrialized countries (dG10FX). The sample is February 1970-December 1989.

time. If there is measurement error which is unrelated to returns, then the measurement error is captured in the residual when the maximum correlation portfolios are formed. We do not form the portfolios from the same set of national equity market returns that we are trying to 'explain,' which should reduce the impact of the overfitting problem with mimicking portfolios (Wheatley, 1989). We use the MSCI international industry indices for this purpose. These are a set of 38 equity indices, formed by industry groups and using the common stocks of firms from many countries in each industry group. (These data are described in more detail in the appendix.)

We examine factor model regressions for the country returns using the maximum correlation portfolios as the factors. Compared with Table 2, the explanatory power of the regressions are slightly higher for most, but not all of the countries. The smallest $R$-square is $11.8 \%$ and the largest is $85.9 \%$. The higher $R$-squares are consistent with the existence of measurement error in the economic data which is unrelated to stock returns.

Given mimicking portfolios for the risk factors, the model implies that the $\lambda_{j}$ are their expected excess returns. However, the MSCI industry indices do not include dividends, so the average returns of portfolios formed from these indices are not good estimates of the risk premiums. This is a problem similar to what Stambaugh (1983a) calls 'mean deficiency.' We handle the mean deficiency by treating the proxy portfolios the same way as we do the economic risk variables in the SURM; namely, we use their de-meaned values and we estimate the risk premiums as separate parameters. As the dividend component of the return is relatively smooth, its absence from the industry indices should not much affect estimates of the covariances. 


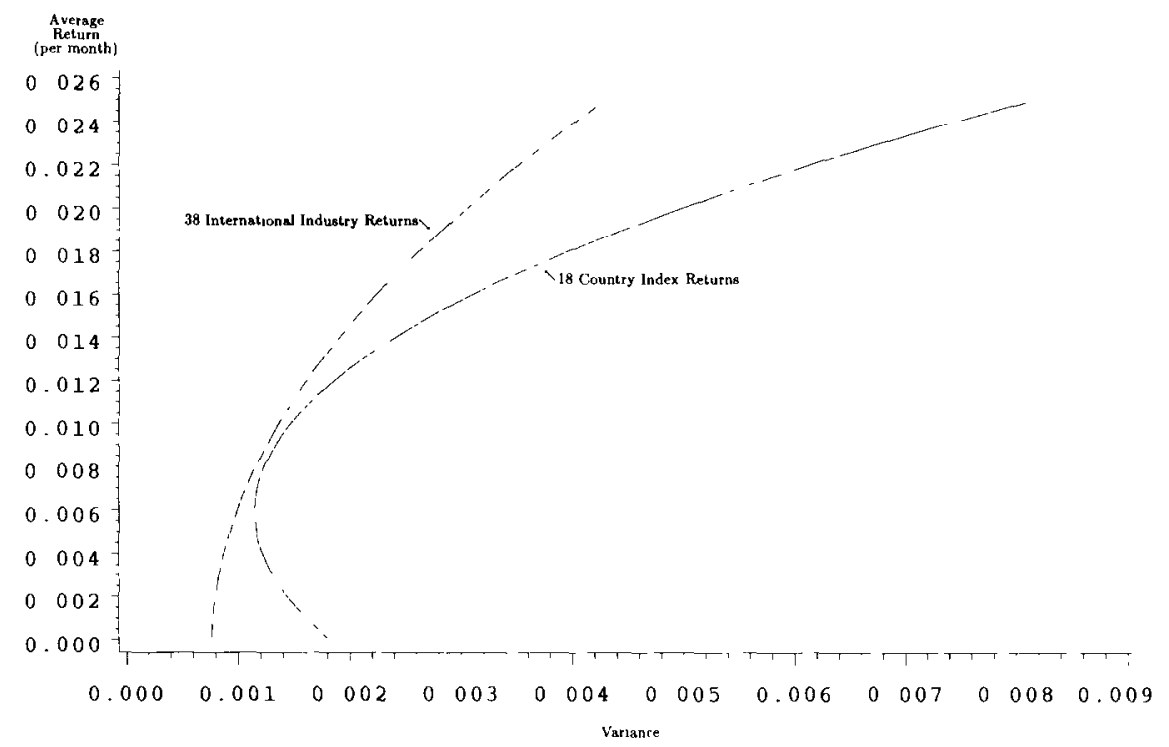

Fig. 4. Two unconditional minimum variance frontiers. The solid curve is calculated using the returns on 18 country portfolios. The dashed curve represents the unconditional minimum variance frontier calculated using 38 international industry returns. The industry returns do not include dividends. The sample is February 1970-December 1989.

Comparisons with the previous tables provides further evidence on the robustness of our results.

For pricing purposes the proxy portfolios should be maximally correlated with the state variables in the universe of test assets (Breeden, 1979). However, since we do not include the country returns in the proxy portfolios, it is possible that higher correlation with the state variables could be obtained. This can be interpreted in terms of the familiar mean-variance diagram, as in Fig. 4. If a set of factor portfolios determine the expected returns in a multi-beta model, a combination of them lies on the minimum variance boundary of all asset returns (Chamberlain, 1983; Grinblatt and Titman, 1987). Introducing additional assets will in general expand the minimum variance boundary. If the efficient combination of our proxy portfolios lies inside the minimum variance boundary of the test assets, then a combination of the portfolios will not price the test assets. Fig. 4 shows that the unconditional minimum variance boundary formed from the industry indices contains the boundary formed from the country returns. ${ }^{17}$

\footnotetext{
${ }^{17}$ If the industry returns were shifted up by an amount, approximately reflecting the missing dividend yield, it is clear from Fig. 5 that the country index boundary would still be contained within the adjusted boundary. Of course, the figure does not account for any estimation error in the boundary, which may be large.
} 
The results of the SURM using the maximum correlation portfolios are qualitatively similar to those of Table 3 . We do not reject the efficiency of a maximum correlation portfolio for the world index using the standard goodness-of-fit test, but the average pricing errors for some countries are large. The mean absolute and weighted mean pricing errors are somewhat smaller than in Table 3, and they are reduced dramatically when we examine the multiple beta model. Introducing the maximum correlation portfolios for the other factors does not diminish the significance of the world market portfolio risk premium in the SURM. As in Table 3, the point estimate of its premium is higher in the multiple beta model. ${ }^{18}$

One interesting difference between the results using the global economic risk variables and using the maximum correlation portfolios involves the industrial output variable $\mathrm{dG} 7 \mathrm{IP}$. Its proxy portfolio produces the largest of the average risk premiums in the SURM, which has a $t$-ratio of 1.7 . This suggests that the output variable may contain measurement errors that are important and are cleaned up to some extent by a maximum correlation portfolio. Shah (1989), Fama (1990), Schwert (1990) and Kothari and Shanken (1992) find that stock returns in the US are sensitive to changes in expected future output. Harris and Opler (1990) and Beckers (1991) extend such results to international data. We therefore conduct experiments in which we replace dG7IP by a one-year leading growth rate. Univariate and multivariate factor model regressions using this variable are jointly significant and the betas on this variable are significantly different across the countries.

We investigate the unconditional pricing results using the 12-month leading output growth rate as an additional risk factor. In the multivariate SURM the betas on the leading production variable do not seem to be marginally important. The premium estimate is $1.25 \%$ per month but the standard error is $1.16 \%$. The world market premium estimate is not changed much by the introduction of the leading production variable. Using the maximum correlation portfolios, including one for the leading industrial production variable, we find generally similar results. In this case, however,

\footnotetext{
${ }^{18}$ The joint tests for zero betas and for betas that are equal across the national markets, like in Table 2, are conducted using the proxy portfolios in place of the economic variables. Only the portfolios for the variables dOIL and dG7RTB fail to produce significant regression betas. We therefore use six factor portfolios in most of these experiments. We have also replicated the SURM's using four maximum correlation portfolios for the variables that were examined in Table 3. We find similar results for the average pricing errors and the test statistics. The estimates of the world market premium and the other premiums are also similar to those of the six maximum correlation portfolio model. The main difference is that the premium for dG10FX is $1.38 \%$ per month in the six factor model and only $0.244 \%$ in the four factor model. Neither of these is more than two standard errors from zero.
} 
the premium on the leading output factor is significant, at $2.97 \%$ per month (standard error $=1.20 \%$ ).

\section{Concluding remarks}

We empirically examine multiple beta models for the returns and expected returns on eighteen national equity markets using a set of factors chosen to measure global economic risks. Although previous studies do not reject the unconditional mean-variance efficiency of a world equity market portfolio, we find that the world market betas provide a poor explanation of the average returns across countries. Our tests do not reject the hypothesis that the returns are consistent with a four-factor model. The average pricing errors of the multiple-beta model are only $0.2 \%$ per month for Japan and $0.1 \%$ for Hong Kong, which are much smaller than the errors of a model based on only the world market portfolio. This suggests that when the measures of risk are expanded to include such variables as exchange rates, oil prices and long-term inflationary expectations, then much of the seemingly abnormal average performance of the Japanese and Hong Kong markets may be explained as compensation for global economic risk.

\section{Appendix}

\section{A. Equity returns}

We use the Morgan Stanley Capital International (MSCI) equity indices. MSCI tracks 21 national indices of which we use 18 (Finland, Mexico and New Zealand are excluded because their data histories are shorter). Stocks from non-domiciled companies and investment funds are excluded from individual country indices. Companies with restricted float due to dominant shareholders or cross-ownership are avoided. However, there are 51 stocks from Finland, Norway, Sweden and Switzerland that are restricted. The overall weight of these restricted stocks is small, and Schmidt (1990) finds that there is little difference in the national indices when these restricted stocks are excluded. All indices have a common base of 100 in December 1969. The indices are constructed using the Laspeyres method which approximates value weighting. U.S. dollar returns are calculated by using the exchange rates available at 4:00 p.m. Central European Time. We use the MSCI world industry portfolios to construct maximum correlation portfolios for the economic variables. MSCI tracks 38 industry groups. These are: Aerospace and Military Technology, Appliances and Household Durables, Automobiles, Banking, Beverages and Tobacco, Broadcasting and Publishing, Building Materials and Components, Business and Public Services, 
Chemicals, Construction and Housing, Data Processing and Reproduction, Electrical and Electronics, Electronic Components and Instruments, Energy Equipment and Services, Energy Sources, Financial Services, Food and Household Products, Forest Products and Paper, Gold Mines, Health and Personal Care, Industrial Components, Insurance, Leisure and Tourism, Machinery and Engineering, Merchandising, Metals (Non-Ferrous), Metals (Steel), Miscellaneous Materials and Commodities, Multi-Industry, Recreation, Other Consumer Goods, Real Estate, Telecommunication, Textiles and Apparel, Transportation-Airlines, Transportation-Road and Rail, Transportation-Shipping, Utilities-Electrical and Gas, and Wholesale and International Trade. All of the world industry indices have a base value of 100 in December 1969. The indices are calculated in U.S. dollars but do not include dividends. Both the industry and national indices are calculated in excess of the 30-day U.S. Treasury bill which is available from Ibbotson Associates. The correlations of the maximum correlation portfolios and the MSCI world index (wrdret) are shown below:

$\begin{array}{lllllrlrrr}\text { CORRELATIONS OF THE MAXIMUM CORRELATION PORTFOLIOS } \\ \text { wrdret } & 1.000 & 0.997 & 0.318 & 0.557 & 0.000 & 0.478 & 0.165 & -0.103 & 0.251 \\ \text { mwrdret } & & 1.000 & 0.319 & 0.559 & 0.000 & 0.479 & 0.166 & -0.103 & 0.252 \\ \text { mdted } & & & 1.000 & 0.095 & -0.143 & 0.272 & -0.120 & -0.118 & 0.146 \\ \text { mdG10fx } & & & & 1.000 & -0.044 & 0.147 & 0.118 & -0.080 & 0.189 \\ \text { mG7ui } & & & & & 1.000 & 0.065 & -0.018 & 0.210 & -0.560 \\ \text { mdG7elt } & & & & & & 1.000 & -0.282 & 0.004 & -0.155 \\ \text { mdoil } & & & & & & & 1.000 & -0.053 & 0.304 \\ \text { mdG7ip } & & & & & & & & 1.000 & -0.173 \\ \text { mG7rtb } & & & & & & & & & 1.000\end{array}$

\section{B. The world risk factors}

WDRET $=$ The world return is the arithmetic return on the Morgan Stanley Capital International world equity index (including dividends) less the Ibbotson Associates one month bill rate.

dTED $=$ The change in the Eurodollar-Treasury yield spread is the difference between the 90-day Eurodollar yield (Citibase FYUR3M) and the 90 day Treasury bill yield (Citibase FYGM3 secondary market, converted from discount to true yield to maturity).

$\mathrm{dG} 10 \mathrm{FX}=$ The change in the $\mathrm{G}-10$ foreign exchange rate is the difference in the trade weighted dollar price of foreign exchange for 10 industrialized countries (G-7 plus the Netherlands, Belgium, Sweden, and Switzerland) (Citibase FXG10).

G7UI $=$ The unexpected inflation for the G-7 countries is derived from a time-series model applied to an aggregate G-7 inflation rate. The G-7 inflation rate is constructed by weighing the individual countries' inflation rates (Citibase: PC6CA, PC6FR, PC6IT, PC6JA, PC6UK, PC6WG and 
ZUNEW) by their shares in the previous quarter's real U.S. dollar G-7 gross domestic product. These weights change through time. The time series model is a seasonal ARIMA(0,1,2)(0,1,2) and the parameter estimates are:

\begin{tabular}{llll} 
& Parameter & Std. error & \multicolumn{1}{c}{$t$-ratio } \\
Intercept & 0.000005 & 0.000057 & 0.10 \\
MA1,1 & 0.432613 & 0.061754 & 7.01 \\
MA1,2 & 0.271394 & 0.061544 & 4.41 \\
MA2,1 & -0.305806 & 0.065162 & -4.69 \\
MA2,2 & -0.180382 & 0.065377 & -2.76
\end{tabular}

The parameters are estimated with 250 monthly observations. The chisquare test for significance of the first six residual autocorrelations has a $p$ value of 0.111 and the corresponding statistic for the first 12 autocorrelations has a $p$-value of 0.275 .

dG7ELT $=$ Change in long term expected G-7 inflation is a result of projecting the four year moving average of G-7 inflation on a set of predetermined instrumental variables. The predetermined instruments are (1) the level of one-month short-term U.S. Treasury bill yield, (2) the dividend yield of the MSCI value-weighted world stock market index, (3) a spread between the yields to maturity of ten-year U.S. Treasury bonds and 90-day U.S. Treasury bills, (4) the lagged value of the Eurodollar (TED) - U.S. Treasury spread, (5) the lagged return on the MSCI world market index, and (6) a dummy variable for the month of January. The regression models the expected long term inflation and dG7ELT is the first difference of the fitted values of the regression.

$\mathrm{dOIL}=$ The change in the natural log of the average U.S. dollar price of per barrel at the wellhead from 1974-1989 and the posted West Texas Intermediate price from 1969-1973. Since the West Texas price is consistently higher than the average wellhead price, the 1969-1973 data is grossed down by $65 \%$. This represents the average premium of West Texas over the average during 1974-1976.

$\mathrm{dG} 7 \mathrm{IP}=$ The change in G-7 industrial production is calculated by weighing local industrial production indices by the following (fixed) factors: Canada 0.04314 , France 0.09833 , Germany 0.05794 , Italy 0.13093 , Japan 0.07485 , U.K. 0.11137 , U.S. 0.48343 which are the weights in G-7 gross domestic product in the third quarter of 1969. The logarithmic difference in this aggregate index is the growth in G-7 industrial production.

G7RTB $=$ The G-7 real interest rate is calculated by aggregating individual countries' short term interest rates. The following interest rates are used (Citibase FYCA3M-Canada 90 day Treasury bill, FYFR3M-France 90 day hill, FYGF.3M-Germany 90 day bill, FYIT6M-Italy 180 day bill, FYCMJPJapan commercial paper 1969-1976 and FYJP3M-Japan Gensaki rate 19771989, FYUK3M-United Kingdom 90 day bill, FYUS3M-United States 90 
day bill.) The aggregate G-7 interest rate is calculated by using the countries's previous quarter's shares in G-7 gross domestic product. The real G-7 interest rate is calculated by subtracting the G-7 inflation rate.

\section{Short term interest rates}

These are used to calculate excess returns in local currency units. The data are as follows: Australia-13 week bill (IFS 61C), Austria-Money market rate (IFS 60B), Belgium-3 month bill (Citibase FYBE3M), Canada-3 month bill (IFS 60C), Denmark-Discount rate 1969-1971 (IFS 60A), Call money rate 1972-1989 (IFS 60B), France-3 month interbank (Citibase FYFR3M), Germany-Frankfurt 90-day rate (Citibase FYWG3M), Hong Kong-No data, U.S. 3-month bill used, Italy-6 month bill (Citibase FYIT6M), Japan-Call money rate 1969-1976 (Citibase FYCMJP), Gensaki rate, 1977-1989 (Citibase FYJP3M), Netherlands-Call money rate 19691978:11 (IFS 60B), 3 month bill 1979:12-1989, Norway-Prime rate 1969 1971:1, Call money rate 1971:12-1989 (IFS60B), Singapore/Malaysia-no data, U.S. bill, Spain-Prime rate 1969-1973:12, Call money rate 1974-1976 (IFS 60B), 3 month bill 1977-1989 (IFS 60C), Sweden-3 month bill (IFS 60C), Switzerland-3 month deposit rate (Citibase FYSW3M), United Kingdom-3 month bill (Citibase FYUK3M), United States-3 month bill (Citibase FYUS3M)

\section{References}

Adler, M. and B. Dumas, 1983, International portfolio selection and corporation finance: A synthesis, Journal of Finance 38, 925-984.

Beckers, S., 1991, Stocks, bonds and inflation in world markets: implications for pension fund management, Journal of Fixed Income 1, 18-30.

Bodurtha, J.N., D. C. Cho and L.W. Senbet, 1989, Economic forces and the stock market: An international perspective, Global Finance Journal 1, 21-46.

Braun, P., D. Nelson and A. Sunier, 1991, Good news, bad news, volatility and betas, unpublished manuscript (University of Chicago).

Breeden, D., 1979. An intertemporal asset pricing model with stochastic consumption and investment opportunities, Journal of Financial Economics 7, 265-296.

Breeden, D.T., M.R. Gibbons and R.H. Litzenberger, 1989, Empirical tests of the consumptionoriented CAPM, Journal of Finance 44, 231-262.

Brown, S.J. and T. Otsuki, 1990a, Macroeconomic factors and the Japanese equity markets: The CAPMD project, in: E.J. Elton and M.J. Gruber, eds., Japanese capital markets, ch. 8 (Harper and Row, New York) 175-192.

Brown, S.J. and T. Otsuki, 1990b, A global asset pricing model, unpublished manuscript (New York University).

Campbell, J.Y. and Y. Hamao, 1992, Predictable stock returns in the United States and Japan: A study of long-term capital market integration, Journal of Finance 47, 43-70.

Chamberlain, G., 1983, Funds, factors and diversification in arbitrage pricing models, Econometrica $51,1305-1324$ 
Chamberlain, G. and M. Rothschild, 1983, Arbitrage, factor structure and mean variance analysis on large asset markets, Econometrica 51, 1281-1304.

Chen, N.-f., R. Roll, and S.A. Ross, 1986, Economic forces and the stock market, Journal of Business 59, 383-403.

Cho, D., C. Eun and L. Senbet, 1986, International arbitrage pricing theory: An empirical investigation, Journal of Finance, 313-329.

Cox, J.C., J. E. Ingersoll and S.A. Ross, 1985, A theory of the term structure of interest rates, Econometrica 53, 385-408.

Cumby, R.E. and J.D. Glen, 1990, Evaluating the performance of international mutual funds, Journal of Finance 45, 497-522.

Dumas, B. and B. Solnik, 1992, The world price of exchange rate risk, unpublished manuscript (Duke University and HEC).

Fama, E.F., 1990, Asset returns, expected returns and real activity, Journal of Finance 45, 1089-1108.

Fama, E.F. and J.D. MacBeth, 1973, Risk, return and equilibrium: Empirical tests, Journal of Political Economy 81, 607-636.

Ferson, W.E. and S.R. Foerster, 1993, Finite sample properties of the generalized method of moments in tests of conditional asset pricing models, unpublished manuscript (University of Washington and University of Western Ontario).

Ferson, W.E. and C.R. Harvey, 1991, The variation of economic risk premums, Journal of Political Economy 99, 285-315.

Ferson, W.E. and C.R. Harvey, 1993, The risk and predictability of international equity returns, Review of Financial Studies 6, 527-566.

French, K.R. and J. Poterba, 1991, Were Japanese stock prices too high? Journal of Financial Economics 29, 337-364.

Gibbons, M.R., 1982, Multivariate tests of financial models: A new approach, Journal of Financial Economics 10, 3-27.

Grinblatt, M. and S Titman, 1987, The relation between mean-variance efficiency and arbitrage pricing, Journal of Business 60, 97-112.

Hamao, Y., 1988, An empirical examination of arbitrage pricing theory: Using Japanese data, Japan and the World Economy 1, 45-61.

Hansen, L.P., 1982, Large sample properties of the generalized method of moments estimators, Econometrica 50, 1029-1054.

Harrıs, T.C. and T. Opler, 1990, Stock market returns and real activity: international evidence, unpublished manuscript (University of California at Los Angeles) November.

Harvey, C.R., 1991a, The world price of covariance risk, Journal of Finance 46, 111-157.

Harvey, C.R., 1991b, The term structure and world economic growth, Journal of Fixed Income 1, 4-17.

Heston, S., G. Rouwenhorst and R.E. Wessels, 1991, The structure of international stock returns, unpublished manuscript (Yale School of Organization and Management) Uctober.

Hodrick, R.J., 1981, Intertemporal asset pricing with time-varying risk premia, Journal of International Economics 11, 573-587.

Huberman, G., S.A. Kandel and R.F. Stambaugh, 1987, Mimicking portfolios and exact arbitrage pricing, Journal of Finance 42, 1-10.

Jorion, P., 1991, The pricing of exchange risk in the stock market, Journal of Financial and Quantitative Analysis 26, 363-376.

Korajczyk, R.A. and C.J. Viallet, 1992, Equity r1sk premia and the pricing of foreign exchange risk, Journal of International Economics 33, 199-219.

Korajczyk, R.A. and C.J. Viallet, 1989, An empirical investigation of international asset pricing, Review of Financial Studies 2, 553-586.

Lehmann, B.N. and M. David M., 1988, The empirical foundations of the arbitrage pricing theory. Journal of Financial Economics 21, 213-54. 
Lintner, J., 1965, The valuation of assets and the selection of risky investments in stock portfolios and capital budgets, Review of Economics and Statistics 44, 13-37.

McCurdy, T.H. and I. Morgan, 1992, Evidence of risk premiums in foreign currency markets, Review of Financial Studies 5, 65-84.

Merton, R.C., 1973, An intertemporal capital asset pricing model, Econometrica 41, 867-87.

Ross, S.A., The arbitrage theory of capital asset pricing, Journal of Economic Theory 13, 341-60.

Ross, S.A. and M. Walsh, 1983, $\Lambda$ simple approach to the pricing of risky assets with uncertain exchange rates, in: R. Hawkins, R. Levich and C. Wihlborg, eds., The internationalization of financial markets and national economic policy (JAI Press, Greenwich, CT).

Schmidt, D., 1990, Morgan Stanley Capital International (MSCI) indices (Morgan Stanley Capital International) spring.

Schwert, G.W., 1990, Stock returns and real activity: A century of evidence, Journal of Finance $45,1237-1258$.

Shah, H., 1989, Stock returns and anticipated real activity, Unpublished Ph.D. dissertation (Graduate School of Business, University of Chicago).

Shanken, J., 1992, On the estimation of beta pricing models, Review of Financial Studies 5, 1-34.

Shanken, J. and M.I. Weinstein, 1990, Macroeconomic variables and asset pricing: Estimation and tests, unpublished manuscript (University of Rochester).

Sharpe, W.F., 1964, Capital asset prices: A theory of market equilibrium under conditions of risk, Journal of Finance 19, 425-42.

Solnik, B., 1983, International arbitrage pricing theory, Journal of Finance 38, 449-458.

Stambaugh, R.F., 1983, Testing the capital asset pricing model with broader market indices: A problem of mean-deficiency, Journal of Banking and Finance 7, 5-16.

Stulz, R.M., 1981a, A model of international asset pricing, Journal of Financial Economics 9, 383-406.

Stulz, R.M., 1981b, On the effects of barriers to international investment, Journal of Finance 36, 923-934.

Stulz, R.M., 1984, Pricing capital assets in an international setting: An introduction, Journal of International Business Studies 15, 55-74.

Wasserfallen, W., 1989, Macroeconomic news and the stock market, Journal of Banking and Finance 13, 613-626.

Wheatley, S., 1989, Testing Asset pricing models with infrequently measured factors, unpublished manuscript (University of Washington).

White, H., 1980, A heteroskedasticity consistent covariance matrix estimator and a direct test for heteroskedasticity, Econometrica 48, 817-838. 